\title{
MENEROPONG GENDER MELALUI KACAMATA GENDERLES: SEBUAH PEMBACAAN BUTLERIAN TERHADAP ANCILLARY JUSTICE KARYA ANN LECKIE
}

\author{
Hana Farida \\ Alumni Universitas Gadjah Mada \\ Email: hanafarida@yahoo.co.id
}

\begin{abstract}
Abstrak
Penelitian ini bertujuan untuk menyajikan bagaimana kategorisasi gender yang terkesan kaku dipresentasikan sebagai performativitas sosial yang cair dan tidak stabil, juga bagaimana norma genderless yang diajukan pengarang dapat menunjukkan pandangannya akan norma gender. Penelitian ini dilakukan dengan menggunakan teori gender milik Judith Butler. Melalui pemikirannya akan gender sebagai konstruksi sosial, Norma gender, terutama gender biner, dalam novel ini dideskripsikan bersama norma genderless untuk mendapatkan suatu perbandingan diantara mereka. Dengan kacamata genderless, norma gender dalam novel ini disajikan pengarang sebagai suatu konstruksi sosial yang menuntut subjeknya untuk terlibat dalam performativitas gender guna diakui keberadaannya. Namun, begitu pula dengan norma genderless. Norma genderless dalam novel ini ternyata juga merupakan bentuk lain dari praktek gender. dengan kata lain, norma genderless tidak bisa terlepas dari gender dan juga merupakan norma gender.
\end{abstract}

Kata kunci: gender biner, kategorisasi gender, genderless

\begin{abstract}
This study aimed to present how the seemingly rigid gender categorization was presented as socially fluid and unstable, as well as how the proposed genderless could show the author's stance toward gender norm. To confirm the suspicion, this study was conducted using gender theory belonged to Judith Butler. Through her thought of gender as a social construction Gender norm, particularly binary gender, in this novel was described along with genderless norm to acquire comparisons between them. Using genderless' point of view, the author presented gender norm in the novel as a social construction which required its subjects to engage in gender performativity in order to be recognized. However, so was the genderless norm. It turned out to be another form of gender practice. In other words, the genderless norm could not completely escape from gender, it was also gender.
\end{abstract}

Keywords: binary gender, gender categorization, genderless

\section{Pendahuluan}

Dalam kehidupan sosial suatu masyarakat, gender memegang peranan yang esensial untuk mengidentifikasi satu sama lain. Identitas gender 'menandai' para anggota masyarakat dalam kehidupan sosial mereka dan menyematkan pada mereka peran sosial yang layaknya mereka jalani. Keragaman gender itu membentuk pengelompokan pada manusia yang memberi gagasan akan karakteristik khusus dari tiap kelompok. Tampilan fisik seringkali dijadikan rujukan atau penanda dalam proses identifikasi gender, menempatkan mereka pada satu kategori gender dan membedakannya dengan kategori lain. Identifikasigender itu dimulai sejak atau bahkan sebelum seorang bayi dilahirkan. Dalam sistem gender biner, penis dan vagina seringkali menjadi penanda utama bagi para tenaga medis untuk menentukan gender si bayi; antara laki-laki dan perempuan. Selain dua organ tersebut, berbagai karakter fisik seperti lekuk tubuh, suara, otot dan rambut pada tubuh dapat membantu identifikasi. Norma sosial pun lalu menuntut mereka untuk mengikuti 'aturan' atas identitas gender yang tersemat. Dalam nilai gender tradisional, laki-laki dituntut untuk bersikap maskulin seperti perempuan yang sepantasnya berlagak feminin. Terdapat stereotip yang mengatakan bahwa; seseorang yang mengenakan lipstick, high heel, dan rok 


\section{Jurnal Poetika Vol. IV No. 1, Juli 2016}

adalah perempuan yang feminine, sedangkan seseorang yang bermain rugby, bersendawa di public, dan berjalan dengan angkuh adalah seorang laki- laki yang maskulin (Lorber, yang dikutip dalam Spade dan Valentine, 2013: 3-4). Stereotip- stereotip seperti itulah yang dikenal oleh sebagian besar masyarakat, Penyimpangan atasnya bisa menyebabkan mereka memberikan respon yang negatif.

Identitas laki- laki dan perempuan pada manusia telah lama menjadi identitas gender yang dikenal dan diakui oleh sebagian besar masyarakat. Kedua gender tersebut atau yang sering disebut sebagai gender biner dan stereotip- stereotip yang menyertainya menjadi identitas yang lazim teridentifikasi. Gender biner tersebut ternaturalisasikan dengan sedemikian rupa sehingga terkesan sebagai identitas gender yang normal dan intelligible bagi manusia. Identitas gender tersebut 'congeal [ed]' over time to produce the appearance of substance, of a natural sort of being (Butler, 2002: 43-44). Mereka seringkali merepresentasikan apa yang disebut normal atau yang seharusnya mengenai seseorang. Dalam dokumen-dokumen resmi, hampir selalu ditemui opsi antara laki-laki atau perempuan untuk dipilih. Bahkan dalam bahasa yang notabene mendefinisikan manusia itu sendiri terkadang hanya mempunyai kata ganti orang yang mengacu pada gender biner tersebut; bahasa Inggris misalnya. Dalam bahasa Inggris, ada dua kata ganti yang mengacu pada orang ketiga; he dan she, masing- masing tertanda sebagai identifikasi atas laki-laki dan perempuan. Selain pengkategorian gender menjadi dua kategori, praktek heteronormativitas juga mengatur preferensi seksual seseorang untuk menjaga stabilitas matriks heteroseksual.

Menurut Butler, The heterosexualization of desire requires and institutes the production of discrete and asymmetrical oppositions between "feminine" and "masculine", where these are understood as expressive attributes of "male" and "female" (Butler, 2002: 23). Lebih, lanjut lagi, dia menambahkan bahwa, certain kinds of "gender identities" fail to conform to those norms of cultural intelligibility, they appear only as developmental failures or logical impossibilities from within that domain (Butler, 2002: 24). Hal inilah yang disebut Butler sebagai compulsory heterosexuality (Butler, 2002: 30).

Butler merupakan teoritikus yang tersohor dengan teorinya mengenai gender sebagai konstruksi sosial. Menurut pemikirannya (Butler, 2004: 42), gender merupakan norma sosial yang dimana norma itu sendiri dapat menentukan intelligibilitas seseorang, mempengaruhi apa yang boleh dan akan muncul dalam domain sosial.

Seorang laki- laki, misalnya, diharapkan untuk berpasangan dengan seorang perempuan. Penyimpangan dari aturan itu dianggap tabu. Intelligibilitasnya sebagai manusia mungkin akan diragukan atau tidak diakui. Melalui praktek- praktek budaya seperti itulah masyarakat mendapati kategorisasi gender biner yang terbatas dan kaku. Namun, kekakuan itu pun lambat laun mulai dipertanyakan.

Sekarang ini, semakin banyak orang yang mulai mempertanyakan kategorisasi gender yang kaku dan mengemukan berbagai kritik atasnya. Sebagian dari mereka menolak kategorisasi pada mereka dan mencoba menyeberang dari satu kategori ke kategori lain. Jumlah orang-orang yang mendeklarasikan 'penyimpangan' mereka semakin merebak. Beberapa orang di US meminta agar gender mereka diklasifikasikan kembali (Meadow, 2010: 815). Sejumlah public figure juga telah mengumumkan pada khalayak mengenai preferensi mereka yang tidak mengikuti sistem gender yang normatif, misalnya: Lance Bass, musisi; Barney Frank, Politisi dari US (gay); Tammy Baldwin, senator dari Winconsin (lesbian), Stacy Ann "Fergie" Ferguson (bisexual), William Beli (drag queen), Carmen Carrera dan Anna Grodzka (transgender). Beberapa Negara, seperti Brazil, Kanada, dan Spanyol telah memberikan izin atas pernikahan homoseksual. Berbagai lembaga juga telah menunjukkan dukungan mereka atas hak masyarakat terhadap praktik gender mereka, antara lain; Tri- Ess (organisasi para crossdresser), dan National LGBTQ Task Force yang mengadakan sebuah konferensi tingkat tinggi 


\section{Jurnal Poetika Vol. IV No. 1, Juli 2016}

di tahun 2008 (Kim, Sheridan, dan Holocomb, 2009: vii). Terdapat juga negara- negara yang mengijinkan secara resmi pencantuman gender ketiga sebagai identitas mereka. German adalah negara pertama di Eropa yang mengakui secara resmi gender ketiga, beberapa negara lain juga telah mengambil langkah yang serupa. Para penduduk Australia memiliki pilihan untuk memilih ' $x$ ' sebagai gender mereka (yang diartikan sebagai tidak tentu, tidak spesifik atau intersex) pada passport mereka sejak 2011. Pilihan yang serupa juga diperkenalkan oleh para penduduk New Zealand di tahun 2012. Di Asia Selatan, Bangladesh menawarkan kategori gender "other" pada permintaan passport sejak 2011. Nepal mulai mengakui gender ketiga pada formulir sensusnya di tahun 2011. India menambahkan kategori gender ketiga pada daftar voternya di tahun 2009 (bbc. co.uk.3January2015). Dengan berbagai aksi tersebut, masyarakat berpotensi memiliki lebih banyak pilihan dan kelenturan dalam menjalankan norma gender.

Sementara itu, di bulan Mei 2011, seorang reporter bernama Jayme Poisson menulis di thestar.com mengenai keberadaan Storm, seorang bayi yang tercatat tidak memiliki gender atau genderless. Pasangan David Stocker dan Kathy Witterick, yang darimana Storm lahir, mencatatkan identitas Storm sebagai "genderless". Tidak ada yang tahu akan gender 'asli' Storm selain mereka, kedua kakak Storm, Jazz dan Kio, dan seorang anggota keluarga dekat. Jazz dan Kio sendiri tercatat sebagai laki- laki. Meskipun begitu, orang tua mereka memberi kebebasan dalam mengekspresikan identitas gender mereka. tidak ada larangan mengenai jenis baju mereka, mainan mereka, ataupun model rambut mereka yang mengikat mereka pada satu identitas gender tertentu. Mereka boleh berambut panjang dan dikepang atau memakai gaun pink yang berenda (www. thestar.com.7oktober2015).

Stocker menginginkan anak- anaknya bebas dari stereotip dan tuntutan norma gender yang bisa mengekang pilihan mereka atas identitas mereka. Tentang Storm, dia menyatakan, "We've decided not to share Storm's sex for now - a tribute to freedom and choice in place of limitation, a stand up to what the world could become in Storm's lifetime." Berita tersebut tersebar cepat dan menuai respon dari berbagai media. Dalam argumennya, seperti yang diberitakan oleh Poisson, Stocker mengatakan, "If you really want to get to know someone, you don't ask what's between their legs" (www.thestar.com.7oktober2015).

Selain Storm, telah ada beberapa orang lain yang berhasil mendapatkan identitas resmi sebagai orang yang bergender netral. Salah satunya, Norrie May-Welby, telah melalui pertarungan hukum yang panjang di tahun 2010 sebelum berhasil mempertahankannya. Jumlah orang yang menginginkan keadaan dimana gender menjadi netral juga semakin bertambah, seperti yang dilaporkan oleh Barbara Kantrowitz dan Pat Wingert (FaustoSterling, 2012: 1).

Sebelumnya isu genderless sudah diangkat dalam beberapa literature, seperti Written on the Body (1992) karya Jeanette Winterson dan The Left Hand of Darkness (1969) karya Ursula K Le Guin. Ancillary Justice sendiri merupakan novel debut hasil karya Ann Leckie yang terbit pada tahun 2013 dan telah mengantarkan berbagai penghargaan ke tangannya, diantaranya Hugo Award, Nebula Award, Arthur C. Clarke Award, Locus Award dan BSFA Award. Genre science fiction pada novel ini mengizinkan Leckie untuk bebas menciptakan dunia imajiner yang berbeda dengan dunia riil namun mudah diterima begitu saja oleh para pembaca.

Dalam Ancillary Justice, Radchaai, atau para penduduk Radch merupakan masyarakat yang tidak menganut norma gender. Breq, ancillary dari Radch, menjumpai orang- orang yang bergender di luar Radch. Breq dulunya merupakan bagian dari angkatan bersenjata Radch yang kemudian hidup sebagai manusia. Orang- orang tersebut didapatinya memakai dua kata ganti (pronoun) dalam system komunikasi mereka, sesuatu yang oleh Breq sulit untuk diterapkan. Oleh karena itu, untuk sebagian besar narasinya, Breq memilih satu pronoun (she) untuk merujuk ke semua orang. 


\section{Jurnal Poetika Vol. IV No. 1, Juli 2016}

Breq melihat gender biner sebagai sesuatu yang asing, sebaliknya norma genderless digambarkan sebagai sesuatu yang familiar. Melalui penggambaran Leckie mengenai norma gender melalui sudut pandang seorang yang genderless, konstruksi gender pun dipertanyakan. Alih-alih menciptakan karya yang membela LGBTQ atau kelompok- kelompok marjinal tertentu seperti yang sudah banyak dilakukan, Leckie memilih menyusuri jalur yang sedikit berbeda. Dia meniadakan norma gender itu sendiri. Dalam ruang imajiner ciptaan Leckie, para pembaca bisa menemukan budaya dimana batas gender terlihat kabur atau bahkan hampir tidak ada. Norma genderless menjadi lensa untuk melihat pola jalinan benang- benang yang membelenggu konstruksi gender.

\section{Konstruksi Gender Biner yang Asing dalam Ancillary Justice}

Masyarakat yang genderless dalam Ancillary Justice diilustrasikan bersama masyarakat lain yang bernorma gender sehingga dapat dilihat perbandingan diantara mereka. Untuk mengilustrasikan bagaimana norma gender terkonstruksi dalam novelnya, Leckie menghadirkan sudut pandang yang netral dari persepsi gender itu sendiri. Oleh karena itu, Breq, yang datang dari budaya tanpa gender bertindak sebagai narrator yang bersama pembaca belajar mengenai bagaimana identitas gender seseorang dapat teridentifikasi. Hanya saja, pengamatan dari sudut pandang yang genderless itu juga mengakibatkan norma gender dihadirkan sebagai norma yang asing bagi para pembaca.

Awal problematika gender dalam novel ditandai dengan pernyataan Breq ketika masuk ke sebuah kedai minuman di Nilt mendapati sekelompok Nilter disana. Breq mengidentifikasi salah seorang dari mereka dengan "She was probably male (3)". Penggunaan "she" untuk laki- laki disini merupakan grammar error yang disengaja. Di sepanjang narasinya yag berbahasa Inggris, Leckie (melalui Breq) hampir selalu mengaplikasikan kata ganti tunggal "she" untuk merujuk pada semua karakternya, baik itu sebenarnya laki- laki ataupun perempuan.

"She", dalam bahasa Inggris, merupakan kata ganti bergender yang merujuk pada sosok perempuan. Sementara itu, "be" lebih lumrah digunakan bila merujuk pada laki- laki. Masyarakat di Nilt sendiri mengakui gender biner untuk mengidentifikasi satu sama lain. Dari keraguannnya, maka jelaslah kedudukan Breq yang tidak familiar dengan norma gender di Nilt. Bagi Breq, dan para penduduk Radchaai darimana dia berasal, gender bukanlah sesuatu yang esensial,

It wouldn't have mattered, if I had been in Radch space. Radchai don't care much about gender, and the language they speak-my own first language-doesn't mark gender in any way. This language we were speaking now did. (3)

Pada awalnya, ketika para pembaca menemui banyaknya kata ganti "she" yang merujuk pada karakter- karakter dalam novel, sangat memungkinkan bagi mereka untuk memutuskan karakter- karakter tersebut berjenis kelamin perempuan. Namun, pernyataan Breq "She was probably male (3)" membuat keputusan itu terkesan salah. Melalui penggunaan yang tidak biasa atas kata ganti bergender ini, Leckie seakan mencoba untuk menerobos batasan gender. Dengan menggunakan bahasa Inggris yang kata ganti bergendernya familiar bagi para penggunanya, Leckie menuntut mereka untuk mempersoalkan konsep gender yang selama ini mereka ketahui. Untuk terus 'membaca' novelnya, Leckie 'mengharuskan' para pembacanya agar menandai kembali penanda yang dimaksud dengan nilai gender yang baru. Hal itu mengimplikasikan suatu upaya atas penghancuran konstruksi gender yang tertanam kuat dalam budaya yang bergender, khususnya gender biner, dan merekonstruksinya ulang dengan wacana yang baru. Gender biner diajukan sebagai norma yang tidak alamiah dan terbuka untuk dimaknai kembali.

Meskipun begitu, Breq tidak bisa menghindar dari kewajiban untuk memakai grammar yang 'tepat' ketika berinteraksi langsung dengan orang- orang bergender itu. 


\section{Jurnal Poetika Vol. IV No. 1, Juli 2016}

Terkadang, Breq beralih dari "she" ke "be" ketika harus berinteraksi langsung. Hal itu perlu dilakukan untuk dapat terlibat dalam interaksi sosial yang membutuhkan identifikasi gender. Namun, kendati cukup menguasai bahasa mereka, Breq masih menemui kesulitan ketika harus mengenali gender lawan bicaranya dan menerapkan kaidah gender yang tepat dalam konteks pembicaraan mereka. Gender, dengan demikian, menjadi sesuatu yang asing dan sulit teridentifikasi bagi pembaca yang hanya bisa melihat apa yang dilihat oleh Breq sebagai sudut pandang mereka.

Dalam mengidentifikasi gender, Breq menyadari bahwa tubuh seseorang (diasumsikan sebagai alat genital) bisa menjadi acuan untuk itu dibuktikan dari argumennya ketika salah menebak gender Strigan, "I can't see under your clothes (104)". Tubuh seseorang, dengan demikian, sering dijadikan penanda untuk menjustifikasi identitas gender yang dimilikinya. Dalam ide Butlerian (Salih, 2003: 62), semua tubuh seseorang pada dasarnya telah disematkan padanya gender sejak awal eksistensi sosial mereka. Ketika keberadaan sosialnya terungkap melalui tubuhnya, maka dia sudah termasuk dalam satu kategori gender yang berisi berbagai ekspektasi sosial. Maka, Breq yang tidak bisa mengidentifikasinya pun kesulitan untuk menentukan identitas gender orang itu.

Seperti yang diimplikasikan dari ide Butler, Leckie menyajikan gender bukan sebagai sesuatu yang natural. Dia menghantam ide tersebut dengan pernyataan Breq selanjutnya bahwa "that's not always a reliable indicator (140)". Dengan kata lain, Breq bisa saja melihat tampilan tubuh seseorang, namun ternyata orang itu memiliki identitas gender yang berbeda dari yang diperkirakannya. Makna gender, dengan demikian, tidaklah kaku, tetapi rentan untuk dimaknai kembali.

Oleh karena itu, menimbang tubuh tidak bisa dijadikan penanda gender, maka Breq harus mengidentifikasi gender berdasarkan ekspresi yang bisa menandai. Butler berpendapat bahwa gender dibentuk secara performatif oleh "ekspresi- ekspresi” yang dikatakan merupakan hasilnya itu sendiri (Butler, 2002: 33). Ekspresiekspresi itu merujuk pada stereotip-stereotip yang mengiringi suatu identitas gender seperti gerak-gerik dan gaya berbicara.

Seseorang juga bisa menilai maskulinitas atau femininitas orang lain melalui gaya berpakaian (Arvanitidou, Zoi dan Maria Gasouka, 2013: 111-112). Rok, misalnya, merupakan pakaian yang hampir selalu identik dengan wanita. Breq juga menebak gender seorang penduduk Nilt sebagai lakilaki berdasarkan "the angular mazelike patterns quilting her (3)". Menurut pengamatan Breq, gaya berpakaian orang itu merupakan sesuatu yang dilakukan oleh laki- laki di Nilt. Dengan demikian, gender -seperti yang dikatakan oleh Butler (Butler, 2002: 33)- adalah 'doing'. Gender bukan merupakan siapa seseorang, tapi apa yang orang itu lakukan.

Namun, Breq tidak selalu berhasil dalam mengenali performativitas gender seseorang. Walaupun dia mengetahui ekspresi tertentu bisa dijadikannya penanda untuk mengenali gender, tanda- tanda itu tidaklah pasti. "it didn't help that cues meant to distinguish gender changed from place to place, sometimes radically, and rarely made sense to me [her](3)". Perubahan itu membuktikan ketidakstabilan norma gender. Ekspresi gender di Nilt belum tentu berarti sama di masyarakat lain.

Di waktu lain, Breq kebingungan menentukan gender para anggota masyarakat karena dia "hadn't learned the trick of it (77). Gender, dengan begitu tidaklah secara natural dan stabil ada pada seseorang dan begitu saja teridentifikasi. Diperlukan, pengetahuan mengenainya yang hanya bisa didapat dari lingkungan sosial dimana identitas itu terkonstruksi. Breq harus 'dididik' atau disosialisasikan terlebih dahulu dengan norma itu agar bisa menjalani kehidupan sosial bersama mereka dengan benar.

Bagi dirinya sendiri, gender tidak bernilai apa- apa baginya. Namun, Breq mau tidak mau harus mengikuti norma yang berlaku dalam interaksi sosial yang dimasukinya demi 


\section{Jurnal Poetika Vol. IV No. 1, Juli 2016}

mengukuhkan keberadaan sosialnya. Martin, juga West dan Zimmerman pernah mengatakan bahwa pengenalan yang sesuai terhadap identitas gender seseorang diperlukan demi menempuh keberhasilan dalam berkomunikasi (Martin 1998; West dan Zimmerman 1987 yang dikutip dalam Lucal 1999: 782). Hal itu nampaknya juga dipahami oleh Breq. Karena kegagalan yang mungkin dilakukannya ketika memenuhi tuntutan sosial akan identifikasi gender, sebisa mungkin Breq berbicara dalam susunan bahasa yang bisa menyelamatkanya dari hal tersebut. Pernah, dia berkata, "I said, still safely in linguistic territory that needed no gender marking (3)". Breq selalu berusaha untuk tidak melakukan kesalahan dalam mengikuti norma gender dengan benar. Kesalahan dalam praktek sosialnya dapat mengancam keberadaan sosialnya. Misgendering yang dilakukan Breq bisa menimbulkan masalah baginya, seperti yang diakuinya, "I could make trouble for myself if I used the wrong forms (3)".

Meskipun demikian, Breq yang kurang bekal pengetahuannya akan gender, tidak bisa mengeksekusi pengetahuan yang baru diterimanya dengan sempurna. Terkadang kesalahan dibuatnya. Seperti yang dilakukannya dengan Strigan -yang walau bukan penduduk Nilt, juga menganut norma gender-,

Since we weren't speaking Radchaai I had to take gender into account-Strigan's language required it. The society she lived in professed at the same time to believe gender was insignificant. Males and females dressed, spoke, acted indistinguishably. And yet no one I'd met had ever hesitated, or guessed wrong. And they had invariably been offended when I did hesitate or guess wrong. (76-77)

Identifikasi gender yang salah pada seseorang yang bergender bisa berarti sebuah penghinaan. Meskipun mereka mengklaim ketidakpedulian mereka mengenai gender, namun gendertampak masih penting. Setidaknya cukup penting sehingga suatu misgendering bisa membuat mereka tersinggung. Selain itu, walau tampaknya tidak ada perbedaan dalam cara mereka berperilaku, perbedaan gender yang ada jelas menunjukkan adanya kategorisasi gender. Hanya saja, kategorisasi itu tampaknya berbeda dengan milik penduduk Nilter, atau lebih tepatnya proses identifikasinya untuk mengenali gender berbeda.

Jika salah satu cara Breq mengidentifikasi penduduk Nilt adalah dengan pola bajunya, maka metode itu tidak bisa dipakai untuk masyarakat yang Strigan menjadi bagian darinya. Cara berpakaian masyarakat itu, seperti yang telah disebutkan, tidak bisa dibedakan. Dengan demikian dapat dismpulkan bahwa norma gender di kedua masyarakat tersebut berbeda, yang semakin membuktikan kecairannya. Identifikasi yang natural atas gender sebenarnya tidak bisa disebut natural. Gender terkesan natural karena ternaturalisasi seiring berjalannya waktu melalui tindakan sosial atau performativitas gender yang berulang- ulang (Butler, 2002: 179). Breq yang tidak tumbuh dalam konstruksi gender, ternaturalisasi untuk mengerti performativitas gender mereka. Gender disajikan Leckie untuk Breq sebagai konstruksi sosial yang perlu diidentifikasi dan dikenali namun membutuhkan keterlibatan sosial untuk mengenalinya.

Terlibat dengan budaya yang bergender, Breq tidak bisa menghindar dari identifikasi gender atas dirinya. Dalam norma gender, berbagai tanda yang ada pada seseorang bisa menuntun pada kesimpulan atas identitas gendernya. Gender yang disimpulkan mungkin saja salah. Namun, suatu hal yang lumrah bagi mereka untuk menempatkan seseorang pada suatu kategori gender tertentu agar bisa merujuknya dengan bahasa mereka. Storm, misalnya, walau tercatat sebagai bayi yang genderless, orang yang tidak tahu atau tidak mau tahu akan secara otomatis mencari tandatanda yang bisa menuntun mereka untuk mengidentifikasi gendernya. Walau diri Breq tahu bahwa dia merupakan seorang Radchaai yang tidak bergender, di mata masyarakat yang menganut norma gender Breq masih terlihat sebagai seorang perempuan. Seperti yang diungkapkan oleh salah seorang penduduk 


\section{Jurnal Poetika Vol. IV No. 1, Juli 2016}

Nilt ketika menyapanya, "Aren't you a tough little girl (2)". Interpelasi itu menunjukkan eksistensi Breq yang membawa tanda- tanda seorang perempuan yang pastinya dikenali oleh penduduk Nilt. Breq sendiri tidak pernah menunjukkan bahwa dia sedang melakukan performativitas gender. Namun, dia juga tidak pernah menyangkal hal itu. tidak seperti ketika mereka mencurigainya sebagai seorang Radchaai yang dengan cepat disangkalnya (4). Hal yang bisa disimpulkan dari fakta tersebut adalah keengganan Breq jika identitasnya sebagai seorang Radchaai terungkap. Oleh karena itu, menerima interpelasi atas identitas gendernya mungkin merupakan pilihan yang bijak untuk membaur dalam kelompok sosial mereka dan dideskripsikan dalam bahasa mereka.

\section{Norma Genderless: Hidup di luar Kategori Gender}

Dalam AncillaryJustice, ideketiadaangender dalam kehidupan sosial termaterialisasikan melalui sistem sosial di Radch. Masyarakat Radchaai, yang mana Breq dulunya adalah bagian darinya, memiliki budaya yang tidak bergender. Dengan dipakainya sudut pandang Breq yang tidak bergender sebagai sudut pandang default, norma genderless pun memungkinkan diterima pembaca sebagai suatu kondisi yang lumrah dan normal.

Sebagai masyarakat yang tidak bergender, maka 'dihilangkanlah' oleh Leckie tanda- tanda pada mereka yang bisa menginformasikan identitas gender yang mungkin dimiliki pada pembaca tidak ada informasi mengenai alat genital mereka, atau ciri/ lekuk tubuh yang bisa dijadikan sebagai petunjuk atas performativitas gender mereka. Terkadang keterangan mengenai fisik diberikan oleh Leckie, namun deskripsi seperti dark brown eyes (bermata coklat), dark skin (berkulit gelap) atau gray haired (berambut abu- abu) bukanlah tanda yang bisa membantu mengenali gender pemiliknya. Bahkan, pakaian yang mereka kenakan pun dibuat netral dari stereotip gender oleh Leckie.

Beberapa kali disebutkan mengenai Radchaai yang memakai celana sebagai pakaian mereka sehari- hari. Celana, sekarang ini merupakan busana yang penggunaannya semakin netral antara laki- laki dan perempuan. Seperti yang disebutkan oleh Arvanitidou dan Gasouka (Arvanitidou dan Gasouka, 2013: 113), dulu celana merupakan kode budaya yang eksklusif bagi kaum laki- laki. Sampai pada tahun 1850 ketika para perempuan sering terlihat dengannya. Kini, celana yang dipakai laki- laki atau perempuan merupakan pemandangan yang lazim. Pemilihan busana yang netral ini bisa dilihat sebagai salah satu upaya Leckie untuk melepaskan Radchaai dari tanda- tanda gender.

Apabila para penduduk Radchaai itu ditempatkan di hadapan norma gender seperti Breq, mungkin saja mereka akan tergenderkan. Namun, di Radch, nilai dan norma gender tidaklah dipermasalahkan. Tidak ada praktek sosial yang mengindikasikan nilai gender. Bahkan, bahasa yang mereka gunakan tidak mendeskripsikan mereka dalam konstruksi gender. Singkatnya, Leckie menyajikan masyarakat Radchaai sebagai masyarakat yang tidak terbagi dalam kategorisai gender.

Bagi Strigan yang bernorma gender, ketiadaan kategorisasi gender mungkin diterima sebagai gender yang sama. Dia bertanya- tanya tentang proses reproduksi mereka,

"I used to wonder how Radchaai reproduced, if they were all the same gender."

"They're not. And they reproduce like anyone else." Strigan raised one skeptical eyebrow. "They go to the medic," I continued, "and have their contraceptive implants deactivated. Or they use a tank. Or they have surgery so they can carry a pregnancy. Or they hire someone to carry it."

None of it was very different from what any other kind of people did, but Strigan seemed slightly scandalized. "You're certainly Radchaai […]” (104)

Sementara dalam compulsory heterosexuality sesorang dituntut untuk menyukai lain jenis atau heteroseksual, budaya genderless di Radchaai memungkinkan penduduknya untuk bebas memilih pasangannya. Bahkan, tidak ada ket- 


\section{Jurnal Poetika Vol. IV No. 1, Juli 2016}

erangan mengenai seksualitas mereka. Mereka bisa saja heteroseksual, homoseksual, biseksual atau bahkan aseksual, tidak ada yang mempermasalahkannya. Sejak awal bahkan tidak ada lakilaki atau perempuan untuk menentukan hal itu. mereka hanyalah Radchaai, manusia.

Sementara itu, rahim selalu diidentikan sebagai organ eksklusif perempuan. Keadan itu seringkali memposisikan perempuan sebagai korban. Mereka sering dituduh mandul, atau dituntut untuk melahirkan anak dan menjadi ibu. Dalam banyak kasus kemandulan, perempuan seringkali dikambinghitamkan walau pada kenyataannya lebih dari separo kasus itu disebabkan factor dari pihak laki- laki (Inhorn dan Birenbaum-Carmeli, 2008: 104). Posisi tersebut mungkin tidak akan ditemui di Radch karena banyak prosedur medis yang bisa dipilih untuk memiliki keturunan. Dengan menyewa rahim orang lain, seseorang bahkan bisa menjadi "ibu" tanpa berkewajiban melahirkan sendiri. Makna "ibu" pun bergeser, menghapuskan pemaknaan lama akan motherhood. Di Radch sendiri, kata ibu digunakan untuk merujuk pada semua orang tua dan tidak diterangkan apakah mereka perempuan atau juga laki- laki. Kondisi tersebut didukung oleh teknologi tinggi yang mereka miliki seperti yang ditunjukan melalui kutipan di atas.

Teknologi itu juga berperan besar dalam misi imperialism dan civilisasi mereka atas bangsa lain. Dalam misi tersebut, Radchaai manerapkan annexation. Di kamus Oxford, to annex berarti "to take possession and control of a territory, etc, esp by force (Hornby, 1995: 40)". Budaya Radchaai sendiri sebenarnya tidak sama sekali menolak masuknya budaya lain ke budaya mereka, dibuktikan dari banyaknya dewa yang diterima sebagai bagian dari praktek relijius mereka. Kontak sosial yang terus menerus dalam annexation itu seharusnya membuat Radchaai sekaligus kebudayaannya bercampur dengan bangsa lain yang bergender. Radchaai bahkan mengadopsi sejumlah penduduk dari wilayah jajahan mereka; sebagian dibiarkan sebagai manusia sedangkan sebagian yang lain dijadikan ancillary-Breq salah satunya-.
Kendati Radchaai memiliki kemampuan untuk menguasai penggunaan bahasa dan praktek budaya lain, namun, di Radch tidak dapat ditemui jejak gender dalam bentuk apapun. Breq menjadi bukti asingnya gender dalam perspektif Radchaai.

Hal ini menimbulkan pertanyaan mengenai kestabilan wacana genderless itu sendiri. Apabila orang- orang tersebut menjadi penduduk Radchaai dan dituntut untuk menggunakan bahasa Radchaai serta terlibat dalam praktek sosial Radchaai yang genderless, maka norma genderless yang mereka ikuti bukanlah sesuatu yang secara alamiah ada. Hal ini dicurigai sebagi resignification atas gender. Alih-alih memaknai gender sebagai sesuatu yang signifikan, budaya Radch memaknainya sebagai sesuatu yang tidak signifikan. Radchaai dengan sengaja menghindari praktek gender dan menuntut penduduknya untuk terkonstruksi dalam norma genderless. Dalam menjalani kehidupan sosial sebagai Radchaai, orang- orang yang diadopsi tersebut mendapati gendernya tidak lagi teridentifikasi dalam praktik sosial Radchaai. Radchaai tidak mengakui gender dalam eksistensi sosial seseorang sehingga mereka mengundo semua norma gender. Sebagai contoh, adalah Breq, ancillary yang asing terhadap norma gender

Breq yang merupakan ancillary adalah tentara yang dibuat -ditanami berbagi implanuntuk tujuan militer. Seperti robot, Breq mengeksekusi perintah dari atasan secara mutlak dan memiliki kemampuan combat yang tinggi. Robot diartikan oleh Klass sebagai "the manufacturedequivalent of the human (172)". Apabila robot merupakan hasil manufaktur dan Breq awalnya bukan penduduk Radchaai -dengan catatan hanya Radchaai yang genderless-, maka tidak salah bila dikatakan bahwa identitas Breq yang genderless dihasilkan bersamaan dengan proses produksinya. 'Kebenaran' lamanya sebagai subjek yang bergender terhapu dan tergantikan dengan 'kebenaran' baru sebagai Radchaai yang genderless. 


\section{Jurnal Poetika Vol. IV No. 1, Juli 2016}

\section{Kesimpulan}

Dalam Ancillary Justice, pengarang memproposisikan wacana genderless dalam oposisinya dengan norma yang bergender. Gender, terutama gender biner, dalam Ancillary Justice digambarkan oleh pengarang sebagai konstruksi sosial yang tidak natural dan tidak stabil. Identitas gender Breq sebagai seorang perempuan tidak secara alami ada padanya sejak kelahirannya atau ketika dia berada di Radch. Identitas itu tersemat padanya sejak keberadaan sosialnya terungkap pada norma yang bergender. Masyarakat bergenderlah yang ternaturalisasi dengan norma gender dan menganggap gender sebagai identitas yang normal dan intelligible bagi manusia. Gender itu sendiri terkonstruksi dari performativitas yang berbeda dan bisa berubah sehngga tidak stabil. Norma gender baru bisa dipahami Breq setelah dia tersosialisasikan.

Norma genderless yang diajukan untuk 'melihat' konstruksi gender sendiri dihadirkan sebagai identitas alternatif atau bahkan utopia yang memungkinkan suatu masyarakat terbebas dari stereotip, prasangka dan aturan yang harus dipenuhi dari tiap kategori gender, membongkar tembok- tembok pembatasnya. Dengan demikian, wacana genderless dalam novel ini bisa jadi merupakan solusi literatur akan pemikiran Butler yang mempermasalahkan kekakuan kategori gender dan diskriminasi serta kekerasan yang sering terjadi pada kaum gender yang marjinal.

Meskipun demikian, norma genderless dalam Ancillary Justice sama sekali bukan norma yang terbebas dari lingkup gender. Identitas genderless di Radch ternyata adalah akibat performativitas para penduduknya yang menolak praktek gender. Sebagian dari mereka (ancillary) bahkan 'dipaksa' untuk tidak bergender. Demi menjadi penduduk Radchaai, diri orang- orang itu terundone. Karena itu norma genderless di Radch juga bisa dikatakan sebagai konstruksi sosial dan memiliki kekuatan represif untuk mempertahankannya.

Wacana genderless yang disajikan ternyata masih saja memiliki nilai gender. Norma genderless di Radch menuntut para subjeknya utnuk melakukan praktik yang tidak bergender agar dianggap intelligible. Genderless tetap merupakan identitas gender, hanya saja gender ini tidak dikategorikan. Dengan demikian dapat disimpulkan bahwa wacana genderless yang disuguhkan Ann Leckie dalam Ancillary Justice masih merupakan wacana gender.

\section{Daftar Pustaka}

Arvanitidou, Zoi and Maria Gasouka. "Construction of Gender trough Fashion and Dressing". Mediterranean Journal of Social Science Vol 4 No 11 (October 2013). Rome: MCSER Publishing. http://www.mcser. org/journal/ index.php/mjss/article/ viewFile/1276/1305. diakses pada 24 Desember 2015 pukul 12.26.

Butler, Judith. 2002. Gender Trouble: Feminism and the Subversion of Identity. Taylor \& Francis e- Library.

. 2004. Undoing Gender. New York: Routledge.

Fausto-Sterling, Anne. 2012. Sex/ Gender; Biology in a Social World. New York: Routledge.

Hornby, A.S. 1995. Oxford Advanced Learner's Dictionary of Current English. Editor: Jonathan Crowther. Fifth edition.

Inhorn, Marcia C. and Daphna BirenbaumCarmeli. "Assisted Reproductive Technologies and Culture Change". Annual Review of Anthropology. 37 (June 2008), http:// www.gwu.edu/ igis / assets / docs / working_papers/igis_igis08.pdf. diakses pada 6 November 2015 pukul 9.53.

Kim, Robert, David Sheridan and Sabrina Holcomb. 2009. A Report on the Status of Gay, Lesbian, Bisexual and Transgender People in Education: Stepping Out of the Closet, into the Light. Washington DC: National Education Association of the United States.

Leckie, Ann. 2013. Ancillary Justice. New York: Orbit. 


\section{Jurnal Poetika Vol. IV No. 1, Juli 2016}

Lucal, Betsy. 1999. "What It Means to be Gendered Me: Life on the Boundaries of Dichotomous Gender System". Gender and Society, Vol. 13, No. 6 (December 1990), http:/ / www. jstor.org/stable/190440. diakses pada 27 Desember 2015 pukul 14.29 pm.

Meadow, Tey. "A Rose Is A Rose: On Producing Legal GenderClassifications". Gender \& Society, Vol. 24 No. 6, 2010 pp. 814-837. New York: New York University. http://sociology. fas.harvard.edu/files / sociology / files/meadow_genderclassifications. pdf?m=1411565171. diakses pada 4 Oktober 2015 pukul 10.33.

Salih, Sara. 2002. Judith Butler. Taylor \& Francis e- Library

\section{Daftar Laman}

Editors (2013, November 1). "Germany Allows Indeterminate' Gender at Birth”. Web. http://www.bbc.com/news/worldeurope-24767225. diakses pada 3 Januari 2015 pukul 22.54.

Poisson, Jayme (2011, May 21). "Parents Keep Child's Gender Secret”. Web. http://www. thestar.com/life/parent/2011/05/21/ parents_keep_childs_gender_ secret. html. diakses pada 7 Oktober 2015 at 19.37.

Spade, Joan Z. and Catherine G. Valentine. 2013. The Kaleidoscope of Gender: Prisms, Patterns, and Possibilities. US: Pine Forge Press. n.d. Web. https://us.sagepub.com/en us/ sites/default/files/upmbinaries/19287_ Chapter_1. diakses pada 6 April 2015 at 8.03. 